\title{
Democratic Attitude in Education Nurturing Creativity of Children
}

\author{
H. U. Husna Asmara \\ Tanjungpura University Pontianak \\ Pontianak. Kalimantan Barat \\ uraihusna52@gmail.com
}

\begin{abstract}
Human creative very be required for building a family and development nation. A creativity that is defined as something process and in sense product that a dimension individual. Person creative that have the characteristics of the smooth (Fluency), flexibility (Flexibility), original (Originality), decomposition (Elaboration), and formulation return (redefinition). Make person creative need an attitude education, between various attitude education attitude democratic that very important because attitude democratic do not oppressive aspiration and shut down diversity and dissent, creativity sink because of power good rule person old, teacher, or person other than taking effect apart from that not give freedom that as possible to do What that desirable, no detrimental to its development and when there is that Chatter. Attitude democratic give appreciation and opportunities for difference opinion, opinion and action cherished that is based on the fact that correct for the benefit of developing child. The opinion that correct is the opinion that helpful for development not which will trap them in an activity that adverse developments. Principle democracy that needs note is development empathy and concern, the integrity, honesty, respect privacy child and extinguish emotions. Moral that negative. Think realistic do since early. Development attitude optimistic forward depression and low achievement with depression disruption soul could resolve, attitude excuses me need be avoided so that they can optimistic. Develop power create child need to be paid to the skills that helpful mentioned will create skills social and skills speak that supported flavor humorous need note, Besides that friendship with friend coeval important for a child so they could influence a social child, here required exemplary that good.
\end{abstract}

Keywords-education; democratic; creativity; empathy; honesty; privacy; powercreate

\section{INTRODUCTION}

Education is a right and a necessity for all of mankind, even though every person and every nation has a different way of fostering a child but basically want a child to grow and develop normally, even better than normal human beings. Implement science education needs to be strengthened by education and experience associated with less education.

Science education is used as a backrest to carry out educational tasks. While experience plays a role not to repeat the same mistake and used to develop activities that are viewed positively.
Education is one of the "tools" in civilizing human. Through education, people will know everything that is unknown, even to develop itself.

Law No. 2 of 1989 on National Education System in chapter 4 explains that: "National Education aims at educating the nation and developed a complete Indonesian man, the man who is faithful and devoted to God Almighty and noble character, has the knowledge and skill, physical and spiritual health, personality steady and independent and responsibilities of community and nationality".

Referring to the legislation, education seeks to develop the ability of human resources (HR) as a complete Indonesian man, mastered the knowledge and skills so that they can carry out their duties. To be able to perform tasks required creativity. Education is one of the means for a society to change the situation. To achieve these objectives we need a proper way in order to obtain a creative force. Thus the child will be able to establish themselves and to participate in building the nation. We not only get an obedient child but human creative as agents of change in the family and nation-building.

\section{A. Creativity and characteristics of the Creative Kids}

Creativity can be viewed from three angles, namely creativity in terms of the process, in terms of products as well as a dimensional person. In terms of the process refference [1] defines "Creativity is a process that manifests itself in fluency, flexibility in as well in originality of thinking". Refference [2] emphasized in terms of products, namely: "the ability to bring something new existence". Refference [3] emphasized on the corner dementia person namely: Creativity to the abilities that are characteristics of creative people.

Guilford factor analysis suggests there are five qualities that characterize the creative thinking ability, smoothness (fluency), flexibility (flexibility), authenticity (originality) decomposition (elaboration) and reformulation (redefinition). Smoothness is the ability weeks to generate many ideas. Flexibility is the ability to express a variety of solution or approach to the problem. Originality is the ability to put forward the idea in ways that the original, not a cliché. Elaboration is the ability to decipher everything in detail. Redefinition is the ability to review a problem based on a different perspective to what is already known by many people.

From the various definitions of creativity are essentially the creativity of a person's ability to give birth to something new, 
whether it be the idea and the real work, which is relatively different from what already exists.

The psychoanalytic theory assumes that creativity guided by unconscious processes. Creativity is a manifestation of psychopathology. Theory Assisi views creativity as a result of the process of association and combination of the elements that already exist, so as to produce something new. Gestalt theory view creativity as a manifestation of the individual insight into the environment as a holistic (whole). Existential theory suggests that creativity is a process to create something new through meetings or encounters between man to man and man to nature. Interpret interpersonal theory of creativity in the context of the social environment. By placing creator (creator) as an innovator and people around as the party that recognizes the creativity, this theory emphasizes the importance of the value and meaning of a creative work. Value implies a social recognition. Trait theory gives a special place to attempt to identify the traits or characteristics-the main characteristics of creativity. Note the definition Guilford as adherents of this theory.

Refference [4] on the results of his studies have identified 24 creative personality traits, namely: (1) open on new experience; (2) flexible in thinking and response; (3) free in stating opinion or feeling; (4) appreciate fantasy; (5) interest in the activities of creative; (6) has his own opinion and not easily influenced by the opinions of others; (7) has a great sense of know; (8) intolerant of dissent and the uncertain situation; (9) willing to take calculated risks; (10) self-reliant and independent; (11) have a responsibility and commitment to the task; (12) persevering and not easily bored; (13) is not desperate to solve the problem; (14) rich in initiatives; (15) sensitive to the environmental situation; (16) is more oriented to the present and the future than the past; (17) has a self-image and emotional stability are good; (18) interested in things abstract, complex, holistic and enigmatic; (19) had the idea that original; (20) has a broad interest; (21) using the free time to activities that are beneficial and constructive for selfdevelopment; (22) critical to the opinions of others; (23) love to ask good questions; and (24) have a moral and ethical awareness of high aesthetic.

Creativity occurs because of the motivation from within itself (intrinsic motivation) and from outside (extrinsic motivation). Encouragement is the source of creative motivation is not just located behind or beside the individual, but also at the front that is the theological dimension of creative behavior.

\section{B. Stages and Attitudes Education}

Refference [5] say that education in the cultural process includes the steps of pre-figurative, configuration, and postfigurative. In the pre-figurative level of the parents where the child's learning because they are more experienced and knowledgeable, sometimes ignoring the creative coaching. The result is a reliable behavior is the behavior of the parents. In the configuration, the phase is the phase of young people are no longer just learning from their parents, but also learn from others. Parents are not always used as a model, even the attitude of parents have started to question critically, and even they are able to offer a new model. In the phase of the postfigurative role of parents becoming more and more dominant, increasingly even at low tide, in this phase is often called the crisis of authority of parents, parents can learn from young people. A place of learning has been wider open including the print and electronic media creative power is greatly appreciated.

In addition to a phase that has been mentioned above. In carrying out the educational task of education has various attitudes. Among the attitude is the attitude of autocratic, permissive attitude, and democratic attitudes.

Autocratic attitude tends to suppress the aspirations and turn off diversity and dissent. Creativity becomes submerged, every problem solved by power.

Permissive attitude or permissive attitude. Kids are given the widest possible freedom to do what they want to do.

Democratic attitude is a combination of both of the above attitude, is when done letting the child does not undermine the development and forbid if there is a deviation and dangerous for the child. In detail, the democratic attitude recounted below.

\section{Democratic attitude in Fostering Creativity}

The terms in the Qur'an clearer about democratic Shura 'means deliberation. Meaning shura 'is not concerned with the most votes, and stop at the most votes. In that deliberation element, there is an element of fairness, courtesy and discretion are the base of deliberation. Because of the potential for the right does not depend on majority voting. Results of deliberation are firmly running the deliberations. The cornerstone of democratic morality and his bodyguard are binding rules which moral teaching itself.

One of the principles of democratic participation is conscious in life. Others were given the freedom to do anything origin does not conflict with existing corridors or agreements that have been made.

Democracy certainly appreciated and opportunities for dissent but obviously differences of opinion it was not for the sake of dissent itself [5]

The opinions and actions are rewarded are based on true facts and to the interests of the development of the child. An opinion that is helpful and useful are those that are beneficial to children's development, which will not trap them in activities that are detrimental to their development.

Opinions are attacking and insulting personal honor and a sovereign that is not based on the facts need to get a settlement rules or sanctions.

Often parents fixated embrace democratic soft side view, ignoring the loud that the attitude of letting mistakes as if democratic. As a result not of the solution, but let's go on an error, even this can threaten the child's potential.

Efforts should be made to foster creativity and personality of the child in accordance with democratic principles is as follows.

\section{1) Developing Empathy and Concern}


Empathy component consists of emotional reactions and attention to all those other people to develop in children and cognitive reactions, which determines the extent to which children when it grows up able to look at things from the point of view or perspective of others. Kids should be able to distinguish between themselves and their world. Kids clearly see the pain of others. Instinctively children are always trying to alleviate the suffering of others. Time teaches a caring attitude to others, it is not enough just to talk about, but it is taught. Children are also taught to use the democratic attitude.

\section{2) honesty integrity}

Research has shown that children who often lie mostly from households are also often lying. In addition, children who come from homes with minimum supervision or rejected by their own parents more often dishonest [6]. Therefore, teaching children the value of honesty and consistent with the development of their age. An understanding of children about honesty can change, but understanding that we as parents and teachers do not change. Teachers and the need to make the honesty and ethics as material or subject matter.

\section{3) Respect the privacy of children}

Privacy means freedom or privacy. Refference [6] stated "one of the biggest causes of strain between parents and children is the continued increase in the child's desire to be independent, and therefore more and more to have a secret, while the parents insist on maintaining his desire to protect and guide the children." Freedom of children need to be appreciated, but it needs to be explained wisely where you need to know or should do and what they cannot know or did not do.

\section{4) Moral Emotions extinguish the negative (Shame and Guilt)}

Feelings of shame and guilt are not the emotional aspects that should be shunned. Use of the appropriate emotion is important for teachers to teach moral values to children. Guilt is more effective than the fear of punishment. Many studies show that moral consciousness is more effective to control the child's behavior than the threat or fear of the outside. Use of shame and guilt, tailored to the child's temperament. It can also confirm on the parent or the child's family.

\section{5) Thinking Realistically}

Human opportunities for self-deception is almost unlimited. Example of a lot of people know that smoking is harmful, but still, 23 percent of the world's population still smoke. Therefore, it teaches children a realistic way of thinking needs to be done early. Keep in mind that the teaching of thinking realistically does not mean forbid children to have a fantasy or a dream for the future.

\section{6) Develop Optimistic attitude to Counteract Depression and Low Achievement}

The present generation tends to be a lot more compared to previous generations. Increased pessimism makes children more vulnerable to the adverse effects of depression and related problems such as poor academic performance, difficulty making friends, even less so can cause physical illness.
Depression is a mental disorder in a person characterized by slumping feeling like feeling depressed, sad and somber. Pessimists think the opposite way, both considered temporary events, adverse events considered to be permanent, the only good event regarded as fate or chance. They often exaggerate bad events. Much scientific evidence that pessimism even depression can be cured by teaching thinking. Therefore, children need to be taught the optimistic attitude as a way to defend against depression and mental disorders and threats as well as physical. One way is to imagine something exciting and not envision a bleak future. To make an optimistic child at the time of the child should be thoroughly criticized. Blaming overload can lead to guilt and shame. But do not blame may erode completely negate the sense of responsibility and willingness to change.

The optimism comes from a realistic way of thinking and of the opportunity to face the challenge of age-appropriate, and then master the ways of dealing with these challenges. Optimism begins first of teachers in dealing with students. Because children are easier to imitate the deeds and words of his teacher.

\section{7) Developing Child Creativity}

One effort to overcome physical and mental stress is to teach children to use creativity. Teach creativity means we have to teach skills that will be useful in her life and reduce unnecessary suffering. Strong creativity can trigger sensory memories, can create a situation by the hypnotherapist is referred to as a "dream awake." In children, we often see converse with themselves as if they were mentored, someone. To be talking to yourself can be effective, it should be conditioned in mindset and behavior through repetition and coaching. Kids can use creativity exercises to teach children to cope with discomfort or stress psychology. The earlier to teach children how to use the creative power of the greater usefully be obtained. Keep your child can enjoy a creative exercise it.

\section{8) Social skills and Speaking Skills}

Social skills or the ability to be able to relate to other people it can be taught from an early age in children one of the social skills is the ability to speak or converse. These conversation skills help children get into a good association with a person or group. Skills chatted includes a variety of personal information, ask questions to others, expressing interest in, and express acceptance.

\section{9) Importance of Humor}

Humor is one skill that not all people have. Although children have different abilities in presenting jokes or jokes least every child is born with a sense of humor. Showing humor has a different purpose, but humor can help people to be able to relate well to others. And to foster their creativity. Humor can avoid tension and boredom.

\section{0)Friendship}

Received hang out with a group of peers is the most important stage of development that can affect a child's social relationships. Teachers or parents set a good example, even creating an atmosphere so intertwined sense of friendship among children. Provide opportunities for all children to be 
able to get along with their neighbors. Ages three to seven years is the egocentric stage, they define friends are others who are simultaneously engaged in the same activity. Companions for them is to stay close to him. They are looking for a friend to those who can lend using egg toys, or other attributes that do not have. Children assume that like-minded friends with them. In fact, the most important criteria in friendship to each child are sharing information- facts or personal feelings tell each other that is unknown to others.

\section{CONCLUSION}

Educating children to become a creative person is their future efforts to succeed. Many children who become victims of one of the students oriented to forge subject's cognitive aspects alone or comfort those shortly. The grounds are trying to improve self-esteem through praise and appreciation, we become too permissive (let) in terms of discipline and demanding too little. In an effort to give them a world-paced fun as the wild dream, we forget that the stress and discomfort are part of the same importance in the human experience as love and compassion, and when we liberate them from obstacles, we free them of the opportunity to learn about the skills to overcome issues that are important in the face of obstacles and disappointments are inevitable in the future of their world.

Many children who seem to be successful in a lesson but when confronted with the ability to solve problems in new ways not acquire the ability at all. Yet when it issues creatively through life becomes more important the more so in an era of uncertainty.

\section{REFFERENCES}

[1]. Munandar. SCU (1977). Guiding the Gifted and Talented. A Scoping Study. Rajawali: Jakarta

[2]. Barron, F. ((1976) The Psychology of Creativity. In Dedi Supriadi. (1994). Creativity Culture and Development of science and technology. Alfabeta: Bandung

[3]. Guilford, JP. (1977). (1965). "Factors that Hinder Aid and Creativity." Teachers Record

[4]. Dedi Supriadi. (1994). Creativity Culture and Development of Science and Technology. Alfabeta: Bandung

[5]. Zumri Bestado Sjamsuar. (2002). Two Wings of Democracy. Romeo Graphic: Pontianak

[6]. Lawrence E. Shapiro (1997). "How To Raise a Child With A high EQ". A parents' Guide to Emotional Intelligence. Tri Kantjoro interpreter, Jakarta: Gramedia 